OTTO, R.F.; REGHIN, M.Y.; SÁ, G.D. Utilização do 'não tecido' de polipropileno como proteção da cultura de alface durante o inverno de Ponta Grossa PR. Horticultura Brasileira, Brasília, v. 19, n. 1, p.49-52, março 2.001

\title{
Utilização do 'não tecido' de polipropileno como proteção da cultura de alface durante o inverno de Ponta Grossa - PR.
}

\author{
Rosana Fernandes Otto; Marie Yamamoto Reghin; Guilherme Domingues Sá ${ }^{1}$ \\ UEPG, Depto. de Fitotecnia e Fitossanidade, Praça Santos Andrade s/n, 84.010-790, Ponta Grossa, PR. E.mail: srotto@ convoy.com.br
}

\begin{abstract}
RESUMO
O experimento foi realizado na UEPG, Ponta Grossa, PR. Estudou-se o efeito da proteção com 'não tecido' de polipropileno sobre o desenvolvimento, a qualidade e a produção de três cultivares de alface, transplantadas no inverno de 1998. O delineamento experimental foi inteiramente casualizado, distribuído segundo esquema fatorial 3x2 (cultivares x sistema de cultivo), com 5 repetições. As cultivares utilizadas foram Tainá, Elisa e Verônica, cultivadas sob a proteção do 'não tecido' de polipropileno (PP) e em ambiente natural (AN). O uso do 'não tecido' como proteção de plantas de alface resultou em maior peso de matéria fresca de cabeça para todas as cultivares estudadas quando comparado ao AN. Verificou-se, para as cultivares Tainá e Verônica, incremento do índice de área foliar, com conseqüente aumento da biomassa das plantas produzidas sob o 'não tecido'. A cultivar Elisa apresentou limbo foliar com aspecto de estiolamento, perdendo a turgidez rapidamente após a colheita. Possivelmente, os níveis de radiação sob PP foram inferiores ao ponto de saturação fotossintética para a cv. Elisa. Recomenda-se o uso do 'não tecido' para as cultivares Verônica e Tainá, no inverno, para a região de Ponta Grossa, por apresentarem cabeças com ótima qualidade e peso comercial.
\end{abstract}

Palavras-chave: Lactuca sativa L., cultivo protegido, polipropileno, estiolamento, agrotêxtil.

\begin{abstract}
Use of non woven polypropylene protection under lettuce crop during winter season in Ponta Grossa, Brazil.

A field experiment was carried out in "Capão da Onça" School Farm, at the Universidade Estadual de Ponta Grossa in Brazil. The effect of the protection of an spunbonded polypropylene non woven fabric on the development, quality and yield of three lettuce cultivars, transplanted during the winter of 1998 was studied. The experimental design was of complete randomized blocks, displayed in a factorial scheme $3 \times 2$ (cultivars $x$ crop system), with five replications. The cultivars were Tainá, Elisa and Verônica growing under non woven polypropylene protection (PP) and environmental conditions (EC). Greater head fresh weight was observed on woven protected plants. Increased leaf area index (LAI) was observed for 'Tainá' and 'Verônica', with consequent increase of biomass in row cover plants. 'Elisa' showed etiolate leafs, that lost rapidly the turgidity after harvesting. It is possible that the radiation levels under PP were bellow of the saturated photosynthetic point for cv. Elisa. The use the non woven protection for cv. Verônica and cv. Tainá, during winter season of Ponta Grossa`s region is recommended, due to the fact that these plants presented heads with excellent quality and commercial weight.
\end{abstract}

Keywords: Lactuca sativa L., protected cultivation, polypropylene, etiolation, row cover.

\section{(Aceito para publicação em 15 de janeiro de 2.001)}

\begin{abstract}
A alface é a principal hortaliça folhosa no mercado consumidor brasileiro. Nos últimos anos, a produção da cultura tem passado por mudanças significativas, tanto em relação a cultivares quanto aos sistemas de produção. Atualmente, em contraste com o cultivo tradicional no campo, os produtores têm investido cada vez mais no cultivo protegido de alface (estufas, tú-
\end{abstract}

neis, etc.), utilizando mudas de qualidade e diferentes substratos para crescimento.

Nesse sentido, o cultivo de alface sob proteção do 'não tecido' de polipropileno (também conhecido como agrotêxtil) pode ser uma alternativa promissora para o produtor. A técnica consiste na colocação do material diretamente sobre a cultura ou sobre o solo semeado, não necessitando de qualquer estrutura de apoio. Os resultados têm demonstrado aumento na produção, na precocidade e na melhoria da qualidade do produto comercial (Wells \& Loy, 1985; Hemphill \& Mansour, 1986; Jenni \& Stewart, 1989; Fuello et al., 1993; Borosic et al., 1994; Otto, 1997; Otto \& Reghin, 1999; Reghin et al., 2000; Otto et al., 2000a). O uso do agrotêxtil ofe-

${ }^{1}$ Estudande de graduação do curso de agronomia da UEPG, Ponta Grossa, PR. 
rece proteção contra fatores climáticos adversos (Hernández \& Castilla, 1993; Otto et al., 2000b) e contra pragas (Wells \& Loy, 1985; Benoit \& Ceustemans, 1992/3; Gregoire, 1992). Apresenta ainda facilidade no manuseio do material (Otto, 1997) e requer menor investimento inicial, se comparado a outros sistemas de proteção de cultivo.

A realização de trabalhos verificando o efeito do agrotêxtil sobre diferentes espécies hortícolas é algo recente no Brasil. Na produção de mudas de mandioquinha-salsa observou-se efeito benéfico da proteção tendo como resultado a formação de mudas mais uniformes, precoces e vigorosas quando comparadas àquelas formadas sem proteção com agrotêxtil (Reghin et al., 2000). Também, na região de Ponta Grossa, verificou-se maior precocidade e incrementos de até $124 \%$ no peso de raízes tubérosas de beterraba cultivada sob agrotêxtil em relação às plantas não protegidas (Otto \& Reghin, 1999). Em tomate e pimentão, a colocação do "não tecido' sobre as mudas recém transplantadas danificou o ponto de crescimento das plantas, atrasando o início da fase reprodutiva (Foltran et al., 1999), porém resultando em aumento da produção total para o pimentão (dados não publicados).

Nos Estados Unidos e Europa a técnica já é conhecida desde os anos 70, sendo utilizada para diferentes espécies. Em alface, cultivada durante o outonoinverno de Astúrias - Espanha, verificou-se que o uso do agrotêxtil promoveu o aumento do peso de matéria fresca da cabeça em relação ao cultivo sem proteção. Constatou-se também maior precocidade na formação de cabeças (Fuello et al., 1993).

No Canadá, foi verificado que, para alface americana transplantada na primavera, deve-se manter a proteção com o agrotêxtil até a cobertura total do solo pelas plantas, visto que promoveu incremento no peso e firmeza das cabeças de alface sob proteção (Jenni \& Stewart, 1989). O estágio ótimo para retirada da cobertura pareceu depender das temperaturas encontradas, visto que temperaturas excessivas resultaram em necrose e queima das folhas externas.

Entretanto, as respostas obtidas em relação a incremento de produção e melhora da qualidade da alface protegida com agrotêxtil não são unânimes. Durante o período de inverno e sob precipitações fortes e constantes de Córdoba, Espanha, foi verificado estiolamento e danos no limbo foliar das plantas cultivadas sob a proteção, impedindo, desta maneira, a formação da cabeça comercial. Parte deste resultado pôde ser explicado pelo baixo nível de radiação fotossinteticamente ativa incidente nesta época do ano. Nesta condição, os baixos níveis de radiação foram mais prejudiciais às plantas protegidas do que o efeito benéfico do aumento de temperatura de ar e do solo verificados, resultantes do uso da proteção com agrotêxtil (Otto, 1997).

No Brasil, pouco se conhece sobre o efeito da proteção de polipropileno sobre as diferentes espécies hortícolas. Alguns produtores tem usado o material para o cultivo da alface, porém não se conhece se os resultados são semelhantes para os principais grupos da espécie aqui comercializados (alface lisa, crespa e americana). Em Ponta Grossa o prolongado período com temperaturas baixas e a ocorrência de geadas no inverno, dificulta o cultivo da alface em ambiente natural, apresentando perdas e aumento no ciclo da espécie.

Desta maneira, o presente trabalho teve como objetivo estudar a influência do uso da cobertura com 'não tecido' de polipropileno (agrotêxtil) sobre o desenvolvimento, a qualidade e a produção de três cultivares de alface, cultivadas no inverno, na região de Ponta Grossa.

\section{MATERIAL E MÉTODOS}

O experimento foi desenvolvido na Universidade Estadual de Ponta Grossa no inverno de 1998, em um solo podzólico vermelho amarelo textura média. $\mathrm{O}$ inverno da região é caracterizado por temperaturas mínima e máxima de 12 e $20^{\circ} \mathrm{C}$, respectivamente, com ocorrência de geadas freqüentes durante todo o período. O preparo da área consistiu no destorroamento do solo e na incorporação de esterco bovino (5 $\mathrm{kg} \cdot \mathrm{m}^{-2}$ ) com enxada rotativa e no preparo de canteiros. A adubação de base adotada foi de $100 \mathrm{~g} \cdot \mathrm{m}^{-2}$ da formulação 414-8, de acordo com o resultado da aná- lise de solo. Aos 10 e 20 dias após o transplante, realizaram-se as adubações de cobertura com $5 \mathrm{~g} /$ planta de nitrocálcio.

As mudas foram produzidas em bandejas de poliestireno expandido, com 128 células, com substrato comercial e transplantadas em 13/05/98 quando apresentavam quatro folhas definitivas. O espaçamento utilizado foi $30 \times 30 \mathrm{~cm}$, distribuído em parcelas experimentais de $1,20 \times 2,10 \mathrm{~m}$, para todas as cultivares, totalizando de 28 plantas/parcela. O delineamento experimental utilizado foi o inteiramente casualisado, distribuído segundo esquema fatorial $3 \times 2$ (cultivares x sistema de proteção), com cinco repetições.

As cultivares utilizadas foram Elisa (grupo manteiga), Verônica (grupo crespa) e Tainá (grupo americana), cultivadas em ambiente natural (AN) e sob proteção do 'não tecido' de polipropileno (PP) ou agrotêxtil, de coloração branca, com 20 g. $\mathrm{m}^{-2}$.

O agrotêxtil foi colocado diretamente sobre as mudas transplantadas de alface. Para evitar a movimentação do material, utilizaram-se varas de bambu, as quais foram enroladas nas bordas do material e colocadas em contato com o solo.

Para avaliação do trabalho, foram colhidas seis plantas centrais/parcela de cada cultivar. Isto ocorreu aos 47 dias após o transplante para a 'Verônica' e aos 54 dat para a 'Elisa' e 'Tainá'. Neste período iniciou-se o desenvolvimento de Sclerotinia sclerotiorum na área de cultivo, o que fez com que todo o experimento fosse colhido na última data descrita, ainda que somente as plantas sob agrotêxtil houvessem completado o ciclo produtivo.

Para cada planta, avaliaram-se o peso de matéria fresca, o número de folhas e o peso de matéria seca após secagem em estufa a $70^{\circ} \mathrm{C}$.

A área foliar de cada planta colhida/ parcela foi estimada pelo método de Blackman \& Wilson (1951), adaptado para este experimento. Retiraram-se quatro folhas de cada planta, em diferentes fases de desenvolvimento. Em seguida, da parte central de cada folha foi retirado um disco do limbo foliar, utilizando-se um cilindro de metal com $21,88 \mathrm{~cm}^{2}$ de área interna. Os discos 
foram secados em estufa a $70^{\circ} \mathrm{C}$ e pesados. A área foliar foi, então, determinada pela equação

$$
\mathrm{AF}=\frac{\mathrm{ND} \times \mathrm{AD} \times \mathrm{PSL}}{\mathrm{PSD}}
$$

em que: $\mathrm{AF}=$ área foliar da planta $\left(\mathrm{cm}^{2}\right) ; \mathrm{ND}=$ número de discos amostrados; $\mathrm{AD}=$ área do disco $\left(\mathrm{cm}^{2}\right)$; $\mathrm{PSL}=$ peso da matéria seca do limbo foliar $(\mathrm{g})$ e PSD = peso da matéria seca dos discos $(\mathrm{g})$.

Com base nos dados de área foliar, de peso de matéria seca das plantas e de espaçamento, calculou-se o Índice de Área Foliar (IAF), a Biomassa Total (BT, g. $\mathrm{m}^{-2}$ ) e a Superfície Foliar Específica $\left(\mathrm{SFE}, \mathrm{cm}^{2} \cdot \mathrm{g}^{-1}\right)$ para cada uma das plantas avaliadas.

Foi realizada a análise de variância para todas as características estudadas. Para os resultados que apresentaram interação significativa, as médias entre os tratamentos foram comparadas pelo teste Tukey, em 5\% de probabilidade, para cada cultivar.

\section{RESULTADOS E DISCUSSÃO}

A interação entre cultivares $\mathrm{x}$ sistema de proteção foi significativa para todas as variáveis estudas, exceto para número de folhas/planta e SFE.

O uso do 'não tecido' como proteção de plantas de alface resultou em maior peso da matéria fresca de cabeça, para todas as cultivares estudadas, comparativamente ao cultivo em ambiente

Tabela 1. Peso de matéria fresca, biomassa e índice de área foliar das cultivares de alface produzidas em ambiente natural (AN) e sob proteção de 'não tecido' de polipropileno (PP). Ponta Grossa, UEPG, inverno de 1998.

\begin{tabular}{lcccr}
\hline \multirow{2}{*}{ Característica } & $\begin{array}{c}\text { Sistema de } \\
\text { cultivo }\end{array}$ & Elisa & Tainá & Verônica \\
\cline { 2 - 5 } Peso da & AN & $224,6 \mathrm{bA}$ * & $191,7 \mathrm{bA}$ & $141,7 \mathrm{bB}$ \\
matéria & PP & $305,8 \mathrm{aA}$ & $297,9 \mathrm{aA}$ & $292,3 \mathrm{aA}$ \\
\cline { 2 - 5 } fresca, g & $\mathrm{CV}(\%)$ & \multicolumn{3}{c}{9,7} \\
\hline \multirow{2}{*}{ Biomassa, } & $\mathrm{AN}$ & $138,7 \mathrm{aA}$ & $125,4 \mathrm{bA}$ & $91,7 \mathrm{bB}$ \\
g.m-2 & $\mathrm{PP}$ & $146,6 \mathrm{aB}$ & $156,0 \mathrm{aB}$ & $201,5 \mathrm{aA}$ \\
\hline & $\mathrm{CV}(\%)$ & \multicolumn{3}{c}{12,1} \\
\hline \multirow{2}{*}{ IAF, m.m-2 } & $\mathrm{AN}$ & $1,51 \mathrm{bA}$ & $1,13 \mathrm{bA}$ & $1,17 \mathrm{bA}$ \\
& $\mathrm{PP}$ & $1,97 \mathrm{aB}$ & $1,88 \mathrm{aB}$ & $2,75 \mathrm{aA}$ \\
\cline { 2 - 5 } & $\mathrm{CV}(\%)$ & \multicolumn{3}{c}{12,7} \\
\hline
\end{tabular}

* Médias seguidas da mesma letra maiúscula na linha e minúscula na coluna, não diferem estatisticamente entre si, pelo teste Tukey ao nível de 5\% de probabilidade.

natural (Tabela 1). A maior produção das plantas sob agrotêxtil refletiu também em maior número de folhas por planta em relação àquelas cultivadas em ambiente natural (Tabela 2), caracterizando uma maior atividade metabólica, com menor intervalo de dias para emissão de novas folhas.

Resultados semelhantes referentes a maior crescimento das plantas em ambiente protegido vêm sendo verificados por outros autores. Streck et al. (1994), em Santa Maria (RS), verificaram maiores valores para número de folhas para duas cultivares de alface cultivadas sob túnel baixo, no inverno e na primavera, comparadas ao cultivo em ambiente externo. Segovia (1991), durante o inverno de Santa Maria, comparou três cultivares de alface cultivadas em ambiente natural e sob estufa plástica e verificou aumento significativo no número de folhas ao longo de todo o período avaliado para o cultivo em estufa. Printz \& Faus (1988), em Marrocos, relataram incremento de $34 \%$ no peso médio de cabeça de alface cultivada sob 'não tecido', em relação ao cultivo ao ar livre. Fuello et al. (1993), durante o período de outono-inverno de Astúrias, Espanha, verificaram que a utilização do 'não tecido' combinado com cores preta ou branca aumentou em $81 \%$ e $183 \%$, respectivamente, a produção de alface relativamente ao uso exclusivo do "'mulching" preto ou branco.

Entretanto, o incremento no peso de matéria fresca da cabeça não é a única

Tabela 2. Número de folhas por planta e superfície foliar específica (SFE) das cultivares de alface produzidas em ambiente natural (AN) e sob proteção de 'não tecido' de polipropileno (PP). Ponta Grossa, UEPG, inverno de 1998.

\begin{tabular}{|c|c|c|c|c|c|}
\hline \multirow{2}{*}{ Característica } & \multirow{2}{*}{$\begin{array}{l}\text { Sistema de } \\
\text { cultivo }\end{array}$} & \multicolumn{3}{|c|}{ Cultivar } & \multirow{2}{*}{ Média } \\
\hline & & Elisa & Tainá & Verônica & \\
\hline \multirow{4}{*}{ No.de folhas/ planta } & AN & 35,2 & 20,1 & 16,0 & $23,8 \mathrm{a}$ \\
\hline & PP & 39,5 & 24,2 & 20,8 & $28,2 \mathrm{~b}$ \\
\hline & Média & $37,3 \mathrm{~A}$ & $22,2 \mathrm{~B}$ & $18,4 \mathrm{C}$ & \\
\hline & CV (\%) & \multicolumn{4}{|c|}{4,5} \\
\hline \multirow{4}{*}{ SFE, $\mathrm{cm}^{2} \cdot \mathrm{g}^{-1}$} & AN & 108,1 & 91,1 & 127,5 & $108,9 a$ \\
\hline & PP & 137,6 & 121,6 & 137,7 & $132,3 \mathrm{~b}$ \\
\hline & Média & $122,8 \mathrm{~A}$ & $106,3 \mathrm{~B}$ & $132,6 \mathrm{~A}$ & \\
\hline & CV (\%) & \multicolumn{4}{|c|}{10,6} \\
\hline
\end{tabular}

*Médias seguidas da mesma letra maiúscula na linha e minúscula na coluna, não diferem estatisticamente entre si, pelo teste Tukey ao nível de $5 \%$ de probabilidade. 
característica a ser considerada na produção comercial da alface. O limbo foliar deve ser bem formado, isento de lesões, tenro, porém firme. Sob estes aspectos, as cabeças de 'Elisa', produzidas sob a proteção, apresentaram qualidade comercial inferior ao cultivo em $\mathrm{AN}$, ainda que o peso de matéria fresca tenha sido maior sob PP. O uso do 'não tecido' de polipropileno promoveu incremento no índice de área foliar, porém, não houve aumento na biomassa da planta (Tabela 1 ), caracterizando estiolamento das mesmas. Como resultado, verificou-se um limbo excessivamente tenro, que perdeu a turgidez imediatamente após a colheita. Este fato, possivelmente, ocorreu devido aos níveis de radiação solar incidentes sob a proteção serem inferiores ao ponto de saturação de fotossíntese da cultivar. Isto contribui para que os valores de superfície foliar específica (SFE) das plantas cultivadas sob PP sejam maiores que das plantas em AN (Tabela 2), caracterizando folhas mais finas, com menor espessura. Entretanto, esse fator não é desejável para cultivares cujas folhas são naturalmente finas e tenras, com é o caso da 'Elisa', comparada à 'Verônica' ou 'Tainá'. O aumento dos valores de SFE para 'Elisa' resultaram em folhas de qualidade inferior.

Resultados semelhantes foram constatados por Otto (1997), no cultivo da alface sob polipropileno, durante o inverno, em Córdoba, Espanha. Neste estudo, verificou-se que o uso do 'não tecido' de polipropileno $\left(17 \mathrm{~g} / \mathrm{m}^{2}\right)$ reduziu, em média, $20 \%$ da radiação fotossinteticamente ativa (PAR) incidente sobre a proteção. Observou-se ainda que, como no inverno, a inclinação dos raios solares é menor do que em outras estações do ano, os níveis de radiação PAR incidente foram inferiores ao ponto de saturação fotossintética da espécie, resultando em aumento da superfície foliar específica (SFE), sem incremento de biomassa.

No presente estudo, para as cultivares Tainá e Verônica, verificou-se que além do aumento verificado no peso de matéria fresca devido a proteção do polipropileno, as plantas apresentaram incremento significativo na produção de biomassa quando comparadas ao tratamento "ambiente natural" (Tabela 1). Possivelmente, a modificação microclimática devido ao uso da proteção favoreceu o aumento da área foliar, promovendo a captação de radiação, o que resultou em maior produção de fotoassimilados por essas cultivares. Provavelmente, os níveis de radiação sob 'não tecido' de polipropileno foram superiores ao ponto de saturação fotossintética para ambas cultivares na maior parte do dia.

$\mathrm{O}$ incremento relativo de biomassa para a cv. Tainá cultivada sob 'não tecido' comparado ao ambiente natural foi de $24,4 \%$, enquanto que para 'Verônica' foi de $119,7 \%$. É provável que essa diferença seja devido a características morfológicas das cultivares. As plantas da 'Tainá' sob a proteção formaram cabeça comercial, fazendo com que a sobreposição das folhas diminuíssem a atividade fotossintética das mesmas. Entretanto, comparativamente à arquitetura das folhas, a cv. Verônica facilitou a captação de radiação e, consequentemente, resultou em maior produção de fotoassimilados.

Assim, a proteção da cultura da alface com agrotêxtil $\left(20\right.$ g. $\left.\mathrm{m}^{-2}\right)$, durante o inverno de Ponta Grossa, favoreceu o desenvolvimento, a produção e a qualidade das cultivares Verônica e Tainá. As plantas apresentaram não só cabeça bem formada, como também folhas com ótimas características comerciais. Já a cv. Elisa apresentou cabeças de bom tamanho comercial, porém com folhas excessivamente tenras, não sendo recomendável a proteção com o polipropileno para o cultivo no inverno de Ponta Grossa.

\section{AGRADECIMENTOS}

Agrademos a Cia Providência - Divisão Não Tecido, pela cessão do material de polipropileno utilizado neste trabalho.

\section{LITERATURA CITADA}

BENOIT, F.; CEUSTERMANS, N. Ecological vegetable growing with plastics. Plasticulture, v. 95, p. $11-20,1992 / 3$.

BLACKMAN, G.E.; WILSON, G.L. Physiological and ecological studies in the analysis of plant environment. Annals of Botany, v. 15, n. 57, p. 63 - 94, 1951.

BOROSIC, J.; ZUTIC, I.; HEBLIN, D. Spring crops of lettuce, carrot and pak-choi growth under direct covers. In: INTERNACIONAL CONGRESS OF PLASTIC IN AGRICULTURE, 13. 1994, Verona, Italy. Proceedings ..., Verona: ICPA, 1994, 22 p.
FOLTRAN, B.N.; OTTO, R.F.; REGHIN, M.Y. Uso da proteção de "não tecido" de polipropileno sobre a cultura do pimentão, em Ponta Grossa-PR. Horticultura Brasileira, Brasília, v. 17, n. 3, p. 286, novembro 1999. (Resumos).

FUELLO, M.A.O.; BARANDA, A.A.; ARRIETA, A.I. Semiforzado de lechuga con agrotextiles - Producción de otoño-invierno al aire libre. Hortofruticultura, v. 4, p. 37 - 40, 1993

GREGOIRE, Ph. Los no tejidos y la protección contra los insectos y los virus. In: CONGRESO INTERNACIONAL DE PLÁSTICOS EM AGRICULTURA, 12., 1992, Granada. Actas..., Granada: 1992. p. E11 - E18.

HEMPHILL, J.D.D.; MANSOUR, N.S. Response of muskmelon to three floating row covers. Journal of the American Society for Horticultural Science, v. 111, n. 4, p. 513 - 517, 1986.

HERNÁNDEZ, J.; CASTILLA, N. El semiforzado con cubiertas flotantes. Hortofruticultura, v. 4, p. 34 - 36, 1993.

JENNI, S.; STEWART, K.A. Optimal stage of row cover removal for early lettuce and mini carrot production in Southern Quebec. In: NATIONAL AGRICULTURAL PLASTICS CONGRESS, 21., 1989, Florida. Proceedings..., Florida, 1989, p. 263 - 268.

OTTO, R.F. Cubiertas de agrotextil en especies hortícolas: balances térmicos, evapotranspiración y respuestas productivas. Córdoba, España: Universidad de Córdoba. 1997. 157 p. (Tesis doctoral).

OTTO, R.F.; REGHIN, M.Y. Respostas produtivas da beterraba cultivada sob «não tecido» de polipropileno, durante o inverno de Ponta Grossa - PR. Horticultura Brasileira, Brasília, v. 17, n. 3, p. 311, novembro 1999. (Resumos). OTTO, R.F.; REGHIN, M.Y.; TIMOTEO, P.; PEREIRA, A.V.; MADUREIRA, A. Resposta produtiva de duas cultivares de morango cultivadas sob «não tecido» de polipropileno no município de Ponta Grossa - PR. Horticultura Brasileira, v. 18, p. 210-211, julho 2000a. (Suplemento).

OTTO, R.F.; REGHIN, M.Y.; TIMOTEO, P.; PEREIRA, A.V.; MADUREIRA, A. Eficiência do "não tecido" de polipropileno na proteção contra danos de geada na cultura do morangueiro, no município de Ponta Grossa - PR. Horticultura Brasileira, v. 18, p. 208-209, julho 2000b. (Suplemento).

PRINTZ, Ph.; FAUS, A. El forzado con los agrotextiles. Revista Horticultura, v. 40, p. 47 $-53,1988$.

REGHIN, M.Y.; OTTO, R.F.; SILVA, J.B.C «Stimulate Mo» e proteção com Tecido «Não Tecido» no pré-enraizamento de mudas de mandioquinha-salsa. Horticultura Brasileira, Brasília, v. 18, n. 1, p. 53 - 56, março 2000.

SEGÓVIA, J.F.O. Influência da proteção ambiental de uma estufa de polietileno transparente sobre o crescimento da alface. Santa Maria, RS: Universidade Federal de Santa Maria. 1991. 73 p. (Tese mestrado).

STRECK, N.A.; BURIOL, G.A.; ANDRIOLO, J.L. Crescimento da alface em túneis baixos com filme de polietileno perfurado. Ciência Rural, Santa Maria, v. 24, n. 2, p. 235 - 240, 1994.

WELLS, O.S.; LOY, J.B. Intensive vegetable production with row covers. HortScience, v. 20, n. 5, p. 822 - 826, 1985. 